\title{
Adsorption Study of Dye Water Using Poly Vinyl Alcohol Coated Carbon Black as an Effective and Low Cost Adsorbent
}

\author{
Poonam Gehlot (Corresponding author) \\ Enviro-Industrial Lab, Department of Chemistry \\ M.B.M.Engineering College, J.N.V. University, Jodhpur (Raj.), India \\ E-mail: pgehlot21@gmail.com \\ Kailash Daga \\ Associate Professor, Incharge - Department of Chemistry \\ Enviro-Industrial Lab, Department of Chemistry \\ M.B.M.Engineering College, J.N.V. University, Jodhpur (Raj.), India \\ E-mail: kailashdaga1963@yahoo.co.in \\ Rishika Mehta \\ Enviro-Industrial Lab, Department of Chemistry \\ M.B.M.Engineering College, J.N.V. University, Jodhpur (Raj.), India \\ E-mail: rishika.mehta@gmail.com
}

Received: August 18, 2010 Accepted: September 7, 2010 doi:10.5539/ijc.v3n3p56

\begin{abstract}
The aim of the research is to determine the efficacy of using Poly vinyl alcohol (PVA) coated carbon black to treat wastewater having low dye concentration. The effect of $\mathrm{pH}$, conc. and dose on the adsorption isotherm were studied. Studies conducted to assess the ability of PVA coated carbon black to adsorb dye from wastewater was found to be as an much effective adsorbent. Batch kinetic and isotherm experiment were conducted.
\end{abstract}

Keywords: Adsorption, Adsorbents (PVA coated carbon black and AW Carbon), Dye, Isotherms

\section{Introduction}

Coloured dye wastewater arises as a direct result of the production of the dye and also as a consequence of its use in the textile and other industries. There are more than 100,000 commercially available dyes with over $7 \times 10^{5}$ tonnes of dyes produced annually [T.Robinson, 2001]. It is estimated that $2 \%$ of dyes produced annually are discharged in effluent from manufacturing operations whilst $10 \%$ was discharged from textile and associated industries [J.R.Easton, 1995]. The wastewaters discharged from dying processes exhibit high BOD, high COD are highly coloured, hot, alkaline and contain high amounts of dissolved solids [Rajeshwari Sivaraj, 2001]. The disposal of such coloured wastes such as dyes and pigments into receiving waters damages the environment, as they are carcinogenic and toxic to humans and aquatic life [Lee, C. K., 1991; Pappic, S., 2000].

Basic dyes are the brightest class of dyes [Mckay, G., 1988] and are applied widely in small scale industries like textile, carpets and wool industries whose discharge bearing dyes throught effluents are added into natural streams [Anjanaeyulu Y., 2001]. In dying industry above 30-60 litres of water is consumed per kg of cloth dyed and large quantities of effluents are released during process [Rajeshwarisivaraj, 2001]. Its amount is to be about $16 \%$ of the total water consumed in the mill [Namasivayam, 1994].

Various treatment methods for removal of dyes from industrial effluents like coagulation using alum, lime, ferric chloride, ferric sulphate, chemical oxidation methods using chlorine and ozone; and membrane separation methods are in vogue [Namasivayam, 1994]. The selection of the removal method is ultimately dependent upon the technology being validated in terms of sustainability, efficiency, adaptation and cost effectiveness. But these 
technologies have limitations such as high operation and maintenance cost, when dealing with large volume of wastewater with low dye concentration. Based on these criteria adsorption method is considered to be the most suitable for application in India. Activated charcoal is the main adsorbent used in industry. Different physical forms of activated charcoal are produced depending on their application.Granular (GAC) forms to be used in adsorption columns and powder (PAC) forms for use in batch adsorption followed by filteration[Raghuvanshi, 2002]. Adsorption can produce high quality water while also being a process that is economically feasible [Singh, 2001].

Low cost adsorbents like flyash, coal, peat, sawdust [Deo, N., 1993], sawdust [Namasivayam, C., 1997] lignite and wood have received considerable interest because of their local availability and their practically low cost [Anjanaeyulu Y., 2001]. Use of bio-adsorbent like rice husk [Singh, 2001], coconut coir, banana pith [Raghuvanshi, 2001] wheat straw, baggase, saw dust [Deo, N., 1993; Singh, 2001; R.Rajagopal, 1991] used tea leaves, cow dung [K.K.H.Choy, 1999] have been found to be highly effective, cheap and eco-friendly. The objective of the work is to develop a better method for the removal of synthetic dyes using low cost adsorbent. Poly vinyl alcohol is a good hydrophilic polymer and has water-adsorbing capacity. The carbon black used for adsorption is furnace black. The furnace black is obtained from the burning of furnace oil in absence of sufficient oxygen at higher temperature. This carbon black (commonly named furnace black) is in the form of very fine particles.

\section{Materials and Methods}

\subsection{Preparation Of Activated Carbon From Opuntia dellinii}

The activated carbon is prepared from the naturally dried stems of the plants Opuntia dellinii, a desert plant. It was cut into small pieces. These were then treated with concentrated sulphuric acid (five times its volume) and kept in oven at $150{ }^{\circ} \mathrm{C}$ for 24 hours. It was filtered and washed with distilled water repeatedly to remove sulphuric acid (washing tested with two drops of barium chloride solution) and finally dried and powdered using mortar and pestle. The adsorbent is sieved to $40-60$-mesh size and heated at $150{ }^{\circ} \mathrm{C}$ for 2 hours. This adsorbent is also added to polyvinyl alcohol coated carbon black to form a new adsorbent having a fine particle size for removing dyes.

\subsection{Preparation Of Poly Vinyl Alcohol (PVA) Coated Carbon Black}

$1 \mathrm{gm}$ of PVA is dissolved in $10 \mathrm{~mL}$ hot water (10\% solution) as a result gel formation occurs. Now 1, 1.25, 1.5, $1.75 \mathrm{gm}$ of furnace black is added in it to form a thick paste. This paste is then mixed with activated carbon obtained from the dried stem of Opuntia dellinii. Now the thick paste obtained is then dried to form lumps. The lumps are further grinded into fine powder. This powder (PVA coated carbon black) is used as an adsorbing material.

\section{Adsorption Experiment}

The adsorbent-adsorbate system was established at ambient temperature and in Batch mode using stock solution. A comparative study of adsorption of Dye - Aniline yellow (azo dye) on the adsorbents, Activated wood carbon (AWC) and Poly vinyl alcohol coated carbon black (PVA-WC) at different $\mathrm{pH}$ was studied. In the adsorption measurement Dye solutions of different concentrations (from 10 to $40 \mathrm{ppm}$ ) and $\mathrm{pH}$ of 3, 5, 8, 10 and 12 were used. The desired $\mathrm{pH}$ was maintained using dilute $\mathrm{NaOH} / \mathrm{HCl}$ solutions. During experiment the system was continuously stirred and at the end of each experiment the solution was centrifuged and filtered using whatman filter paper. The concentration of the Dye was measured by UV-VIS spectrophotometer at the wavelength of abs. max. $4910 \AA$ at a time intervals 15 to $120 \mathrm{~min}$. The $\mathrm{pH}$ was measured by $\mathrm{pH}$ meter.

\section{Isothermal Study: Known isotherm models like Freundlich and Langmuir isotherm fit the adsorption} equilibrium data of dye

\subsection{Langmuir Adsorption Isotherm}

The Langmuir equation is derived from simple mass-action kinetic, assuming chemisorption. This model is based on two assumptions that the forces of interaction between adsorbed molecules are negligible and once a molecule occupies a site and no further sorption takes place. The saturation value is reached beyond which no further sorption takes place. The saturation monolayer can then be represented by the expression:

$$
\mathrm{C}_{\mathrm{e}} / \mathrm{q}_{\mathrm{e}}=1 / \mathrm{Q}_{\mathrm{o}} \mathrm{b}+\mathrm{C}_{\mathrm{e}} / \mathrm{Q}_{\mathrm{o}}
$$

Where, $\mathrm{C}_{\mathrm{e}}$ is equilibrium concentration $(\mathrm{mg} / \mathrm{L}), \mathrm{q}_{\mathrm{e}}$ is the amount adsorbed at equilibrium time per unit adsorbent $(\mathrm{mg} / \mathrm{g})$ and $\mathrm{Q}_{\mathrm{o}}$ and $\mathrm{b}$ are Langmuir constants related to adsorption capacity and energy of adsorption respectively. 


\subsection{Freundlich Adsorption Isotherm}

The Freundlich equation is used for heterogeneous surface energies in which the energy term, Qo in the Langmuir equation varies as a function of the surface coverage, qe strictly due to variations in the heat of adsorption:

$$
\mathrm{q}_{\mathrm{e}}=\mathrm{k}_{\mathrm{f}} \mathrm{C}_{\mathrm{e}} 1 / \mathrm{n}
$$

The linear form of the equation (1) or the log form is

$$
\log \mathrm{q}_{\mathrm{e}}=\log \mathrm{k}_{\mathrm{f}}+1 / \mathrm{n} \log \mathrm{C}_{\mathrm{e}}
$$

$\mathrm{k}_{\mathrm{f}}$ and $\mathrm{n}$ are Freundlich constants; $\mathrm{n}$ gives an indication of the favorability and $\mathrm{k}_{\mathrm{f}}$ the capacity of the adsorbent. Value of $\mathrm{n}$ between 1 and 10 indicates good adsorption.

The equilibrium concentration was calculated using following formula:

$$
\mathrm{C}_{\mathrm{e}}=\mathrm{C}_{\mathrm{o}}-\left(\% \text { adsorption } \times \mathrm{C}_{\mathrm{o}} / 100\right)
$$

The amount of dye adsorbed per unit weight of an adsorbent $\mathrm{q}$, was calculated using following formula:

$$
\mathrm{q}=\left(\mathrm{C}_{\mathrm{o}}-\mathrm{C}_{\mathrm{e}}\right) \times \mathrm{V} / \mathrm{m}
$$

Where $C_{e}$ is the equilibrium concentration $(\mathrm{mg} / \mathrm{L}), \mathrm{C}_{\mathrm{o}}$ is the initial concentration $(\mathrm{mg} / \mathrm{L}), \mathrm{m}$ is the mass of the adsorbent (gm) and $\mathrm{V}$ is the volume of the solution (l).

The Langmuir and Freundlich constants increase with the rise in temperature. The values of the $\mathrm{n}$ lie between 1 to 10 indicating good sorption potential of the sorbent. The co-relation coefficient (r) for Freundlich and Langmuir isotherms are merely equal. Therefore from the present adsorption study it can be stated that Freundlich and Langmuir adsorption equations are found to be better fitted. $(\mathrm{r} \sim 0.999)$ as shown in table 1 .

\section{Results}

\subsection{Effect of $p H$}

The $\mathrm{pH}$ of the aqueous solution is an important controlling parameter in the adsorption process ${ }^{18}$. The role of Hydrogen ion concentration was observed at different $\mathrm{pH}$ 3-12.The adsorption of Aniline yellow on $\mathrm{AW}$ carbon at conc. of $40 \mathrm{ppm}$ is minimum at lower $\mathrm{pH} 3$, it increases with increase in $\mathrm{pH}$ up to $8(54.2 \%)$. Similarly adsorption on PVA coated carbon at a pH 8 was found to be $62.3 \%$ at a conc. of $40 \mathrm{ppm}$.

\subsection{Effect of contact time}

The data table of amount of dye adsorbed at various intervals of time indicates that the removal of dye (adsorbate) initially increases with time but attains an equilibrium at a certain time interval. It was observed that $\%$ removal decreases with increase in dye concentration.

The AW carbon as an adsorbent of dose 1.5 gm could remove $49.0 \%$ to $79.4 \%$ of Aniline yellow with increase in time interval from 15 to $120 \mathrm{~min}$. at initial dye concentration of $10 \mathrm{ppm}$. While for dye concentration of 40 ppm, the adsorption of dye varied from $25.3 \%$ to $54.2 \%$. Similarly PVA coated wood carbon showed max removal from $52.0 \%$ to $89.1 \%$ with an time interval of 15 to $120 \mathrm{~min}$. at a dye conc. of $10 \mathrm{ppm}$ as shown in figure 1.

\subsection{Effect of initial dye concentration}

It was observed that the \% removal of Dyes decreases with an increase in the concentration of Dyes from 10 to $40 \mathrm{ppm}$.

\subsection{Effect of dose}

The study was done on various doses of adsorbents viz. 1, 1.25, 1.5, $1.75 \mathrm{gm}$. The results reveal that the \% removal rate of 89.1 and $79.4 \%$ of Dye on PVA coated wood carbon and AW carbon resp. was achieved with 1.5 $\mathrm{gm}$ in 100 minutes by adsorbent of adsorbate concentration of $10 \mathrm{ppm}$. But \% removal rate increased to $92.6 \%$ and $82.5 \%$ of dye on PVA-WC and AWC resp.when dose of $1.75 \mathrm{gm}$ of adsorbents were used. Hence the \% removal of dye increases as the dose is increased this is due to the enhanced surface area of the adsorbent. But after a certain dose of adsorbent the maximum adsorption is attained due to the saturation capacity of the adsorbent.

\section{Conclusion}

According to the results, it can be concluded that PVA coated wood charcoal adsorbent is more effective in the removal of dye methylene blue, at low $\mathrm{pH}$ values and concentrations. The adsorbed amount of dye on PVA 
coated wood charcoal, as adsorbent and its adsorption rate are higher than for dye adsorption on AWC as adsorbent.

\section{References}

Anjanaeyulu Y., Himabindu, V. (2001). Application of mixed adsorbent (oxygenated coconut shell, activated carbon, - OCSAC-Flyash-china clay) for the removal of basic dyes from Industrial effluents. $J$ Envt and Pollut., $8(1), 117-127$.

Baes,G.B. and Mesmer, R.E. (1976). Hydrolysis of Cations, John Wiley and Sons, New York.

Deo, N., Ali, M. (1993). Dye adsorption by new low cost material Congo Red. - Indian J Envtl Prot, 13(7), 496-508.

J.R.Easton. (1995). colour in dyehouse effluent, Ed.P.Cooper, Soc.Dyers, colorists, The Alden Press,Oxford.

K.K.H.Choy, G.Mc.Kay, J.F.Porter. (1999). Resour.conserv.Rec., 27,57-71.

Lee, C. K., Low, K. S., \& Gan, P. (1991). Removal of some organic dyes by acid treated spent bleaching earth. Environ Technol, 20, 99-104.

Mckay, G., Elgundi, M., Nassar, M. M. (1988). External mass transport process during the adsorption of dyes on to the Baggasse pith. - Water Res, 22(12), 1527- 33.

Namasivayam, C., Kadirvelu, K. (1994). Coir pith as an agricultural waste byproduct, for the treatment of dyeing wastewater. - Bioresource Technol, 48, 79-81.

Namasivayam, C., Kadirvelu, K. (1997). Activated carbon prepared from coir pith by physical and chemical activated methods. - Bioresource Technol., 62 (3), 123-127.

Pappic, S., Koprivanac, N., Metes, A. (2000). Optimizing polymer induced flocculation process to remove the active dyes from wastewater. - Environ Technol, 21, 97-105.

R.Rajagopal, Colourage. (1991), 38, (1), 50-52.

Raghuvanshi, S. P. (2001). Decolourisation of Dyes and chromium using bioadsorbents, from the aqueous solutions. M. Tech Thesis, Dept of Environmental Sciences \& Engg, Guru Jambheshwar University, Hisar, Haryana, India.

Raghuvanshi, S. P. Raghav, A. K. Singh, R. and Chandra, A. (2002). Investigation of Sawdust as Adsorbent for the Removal of Methylene Blue Dye in Aqueous Solutions, In Proceedings of International Conference for Water and Wastewater. - Perspectives in Developing Countries, (WAPDEC), International Water Association, U. K., 1053-1062.

Rajeshwari Sivaraj, Sivakumar, S., Senthilkumar, P., Subburam, V. (2001). Carbon from cassava peel, an agricultural waste, as an adsorbent in the removal of dyes and metal ions from the aqueous solution. Bioresource Technol, 80 (3), 233-235.

Rajeshwarisivaraj, Namasivayam C., Kadirvelu K. (2001). Orange peel as an adsorbent in the removal of acid violet 17 (Acid Dye) from aqueous solution. - Waste Mgt, 21, pp. 105-110.

Singh, R. (2001). COD reduction from the textile wastewaters using bio-adsorbents. - M.Tech Thesis, Dept of Environmental Sciences \& Engg, Guru Jambheshwar University, Hisar, Haryana, India.

Singh, R. P., Singh Y., Gupta, N., Gautam, A., Singh, S., Chauhan, M. S., Kulshrestha, R. R., Bhati, M. (2001). Decolarization of water containing Crystals Violet, Methylene Blue, Malachite Green and Rhodamine B using activated carbon, flyash, baggase and baggase. - Proc. 10th National Symposium on Environment India, 143-147.

T.Robinson, G.Mc.Mullan, R.Marchant, P.Nigam. (2001). Biores.Technol., 77, 247-255. 
Table 1. Langmuir and Freundlich constants for adsorption of dye on PVA-WC and AWC at 100 min and at optimum dose of $1.5 \mathrm{gm} / \mathrm{L}$.

\begin{tabular}{|c|c|c|c|c|c|c|c|}
\hline \multirow{2}{*}{} & \multicolumn{4}{|c|}{ Langmuir } & \multicolumn{3}{c|}{ Freundlich } \\
\cline { 2 - 8 } & $\mathrm{Q}_{\mathrm{o}}(\mathrm{mg} / \mathrm{g})$ & $\mathrm{B}(\mathrm{L} / \mathrm{mg})$ & $\mathrm{R}$ & $\mathrm{r}^{2}$ & $\mathrm{n}$ & $\mathrm{r}$ & $\mathrm{r}^{2}$ \\
\hline PVA-WC & 19.23 & 0.286 & 0.9874 & 0.975 & 2.54 & 0.996 & 0.994 \\
\hline AWC & 17.54 & 0.183 & 0.9950 & 0.991 & 1.36 & 0.999 & 0.999 \\
\hline
\end{tabular}

r: Correlation coefficient

$\mathrm{r}^{2}$ : Coefficient of determination

Table 2. Data of Langmuir and Freundlich adsorption isotherm for adsorption of dye (PVA-WC).

\begin{tabular}{|c|c|c|}
\hline Adsorbent dose $(\mathrm{g} / \mathrm{L})$ & $\begin{array}{c}\text { Langmuir isotherm } \\
(\text { Linear equation })\end{array}$ & $\begin{array}{c}\text { Freundlich isotherm } \\
\text { (Linear equation) }\end{array}$ \\
\hline $1 \mathrm{~g} / \mathrm{L}$ & $\mathrm{Y}=0.047 \mathrm{x}+1.169$ & $\mathrm{Y}=0.556 \mathrm{x}+0.535$ \\
\hline $1.25 \mathrm{~g} / \mathrm{L}$ & $\mathrm{Y}=0.046 \mathrm{x}+1.169$ & $\mathrm{Y}=0.530 \mathrm{x}+0.573$ \\
\hline $1.5 \mathrm{~g} / \mathrm{L}$ & $\mathrm{Y}=0.052 \mathrm{x}+0.182$ & $\mathrm{Y}=0.393 \mathrm{x}+0.739$ \\
\hline $1.75 \mathrm{~g} / \mathrm{L}$ & $\mathrm{Y}=0.043 \mathrm{x}+1.252$ & $\mathrm{Y}=0.718 \mathrm{x}+0.692$ \\
\hline
\end{tabular}

Table 3. Data of Langmuir and Freundlich adsorption isotherm for adsorption of dye (AWC)

\begin{tabular}{|c|c|c|}
\hline Adsorbent dose $(\mathrm{g} / \mathrm{L})$ & $\begin{array}{c}\text { Langmuir isotherm } \\
\text { (Linear equation) }\end{array}$ & $\begin{array}{c}\text { Freundlich isotherm } \\
\text { (Linear equation) }\end{array}$ \\
\hline $1 \mathrm{~g} / \mathrm{L}$ & $\mathrm{Y}=0.042 \mathrm{x}+0.983$ & $\mathrm{Y}=0.504 \mathrm{x}+0.513$ \\
\hline $1.25 \mathrm{~g} / \mathrm{L}$ & $\mathrm{Y}=0.038 \mathrm{x}+1.153$ & $\mathrm{Y}=0.540 \mathrm{x}+0.454$ \\
\hline $1.5 \mathrm{~g} / \mathrm{L}$ & $\mathrm{Y}=0.057 \mathrm{x}+0.311$ & $\mathrm{Y}=0.0734 \mathrm{x}+0.084$ \\
\hline $1.75 \mathrm{~g} / \mathrm{L}$ & $\mathrm{Y}=0.031 \mathrm{x}+1.084$ & $\mathrm{Y}=0.5185 \mathrm{x}+0.4108$ \\
\hline
\end{tabular}

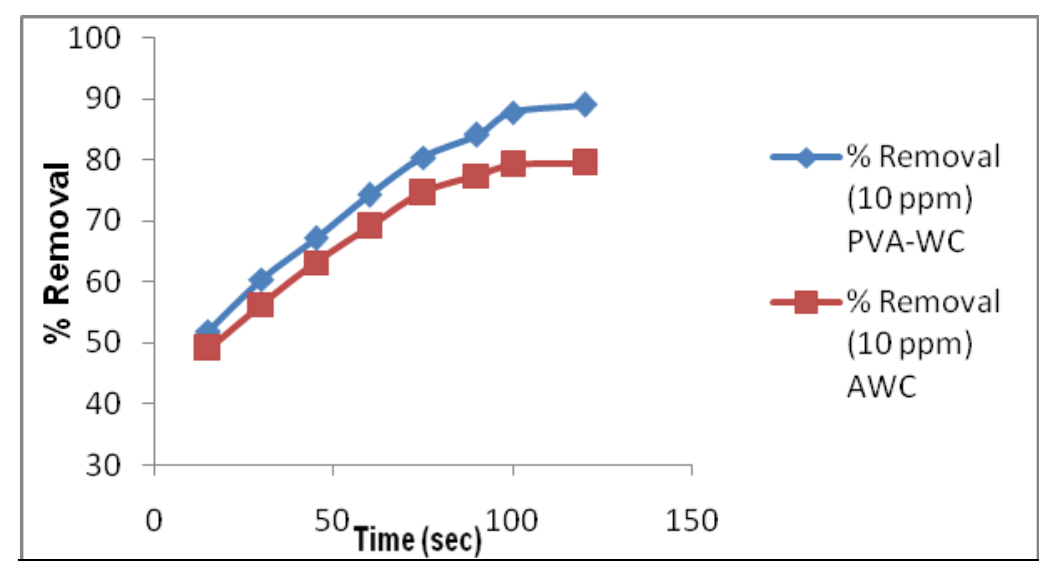

Figure 1. Effect of contact time on adsorption of dye on AWC and PVA-WC at $\mathrm{pH} 8$. (dose $=1.5 \mathrm{gm} / \mathrm{L})$ 


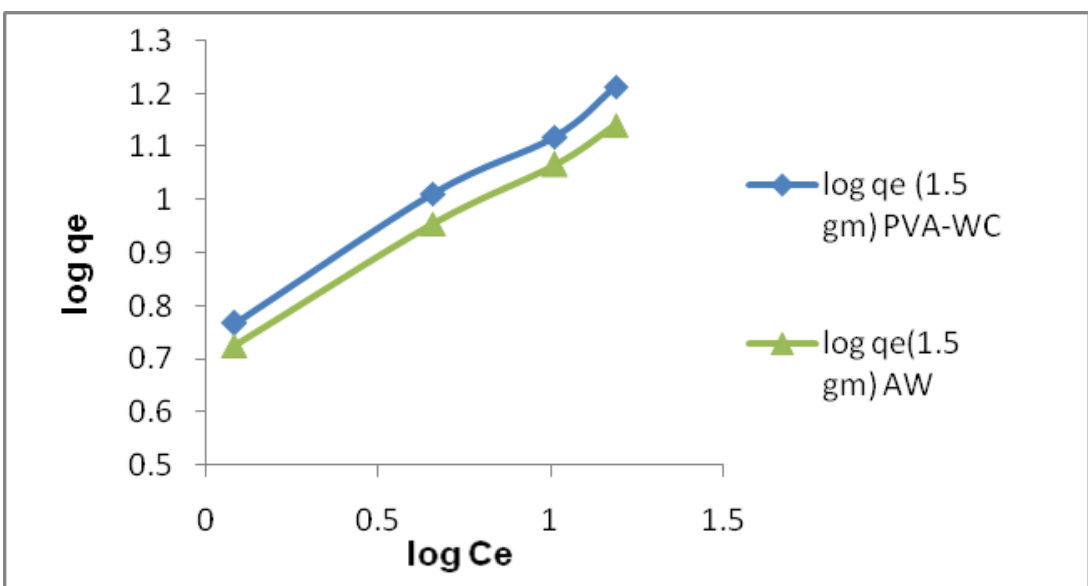

Figure 2. Freundlich Isotherm for effect of different adsorbents on adsorption of dye on PVA-WC and AWC of dose $1.5 \mathrm{gm}$ at 100 minutes

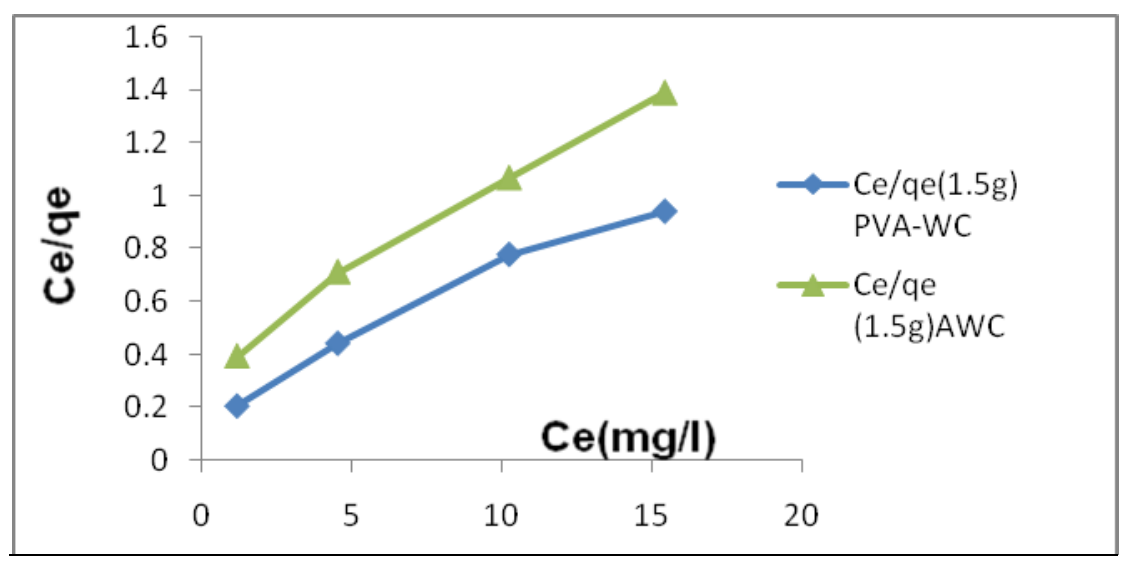

Figure 3. Langmuir Isotherm for effect of different adsorbents on adsorption of dye on PVA-WC and AWC of dose $1.5 \mathrm{gm}$ at 100 minutes 